\title{
Baratas (Insecta, Blattaria) sinantrópicas na cidade de Manaus, Amazonas, Brasil
}

\author{
José Albertino RAFAEL ${ }^{1}$, Neliton Marques da SILVA², Racy Manuel Najar Sarmento DIAS ${ }^{3}$
}

\section{RESUMO}

A coleta de baratas na cidade de Manaus resultou em seis espécies associadas às habitações, estabelecimentos comerciais e educacionais, sendo quatro predominantemente dentro das habitações, Blatella germanica (Linnaeus, 1758), Supella longipalpa (Fabricius, 1798), Periplaneta americana (Linnaeus, 1758), P. australasiae (Fabricius, 1775) e duas fora das habitaçóes, Pycnoscelus surinamensis (Linnaeus, 1758) e Blaberus parabolicus Walker, 1868. P. americana foi comum tanto interna como externamente às instalaçôes urbanas; $P$. australasiae foi predominante em barcos; $P$. surinamensis e $B$. parabolicus foram invasoras ocasionais de residências na estação chuvosa. São apresentadas fotos coloridas, em tamanho natural, para reconhecimento das espécies.

PALAVRAS-CHAVE: Baratas, Insetos, Entomologia urbana, Sinantropia.

\section{Synantropic cockroaches (Insecta, Blattaria) from Manaus, Amazonas, Brazil}

\section{ABSTRACT}

Collection of cockroaches from Manaus resulted in six species associated to human house, commercial buildings and educational buildings, being four species found predominantly indoor, Blatella germanica (Linnaeus, 1758), Supella longipalpa (Fabricius, 1798), Periplaneta americana (Linnaeus, 1758) and $P$. australasiae (Fabricius, 1775) and two species found predominantly outdoor, Pycnoscelus surinamensis (Linnaeus, 1758) and Blaberus parabolicus Walker, 1868 the latter two occasionally houseinfesting species in the rainy season. $P$. americana was common either indoor and outdoor and $P$. australasiae infesting mainly boats. Color figures in natural size are presented for all species in order to help their identification.

KEY-WORDS: cockroaches, insects, sinantropy, urban Entomology.

\footnotetext{
1 Instituto Nacional de Pesquisas da Amazônia, Coordenação de Pesquisas em Entomologia, Caixa Postal 478, 69011-970, Manaus, AM, Brasil. e-mail: jarafael@inpa.gov.br 2 Universidade Federal do Amazonas, Faculdade de Ciências Agrárias, Laboratório de Entomologia Agrícola, Mini Campus, 69070-000. e-mail: nmarques@ufam.edu.br ${ }^{3}$ Bolsista INPA/PIBIC
} 


\section{INTRODUÇÃO}

São conhecidas cerca de quatro mil espécies de baratas no mundo. No Brasil são 644 espécies (Pellens \& Grandcolas, 2008) e a maioria habita a floresta (Princis, 1962-71; Grandcolas, 1998a; Grandcolas \& Pellens, no prelo). Menos de vinte espécies são consideradas sinantrópicas (que vivem associadas ao ambiente humano), e cinco destas, Blatella germanica (Linnaeus, 1758), Supella longipalpa (Fabricius, 1798), Periplaneta americana (Linnaeus, 1758), P. australasiae (Fabricius, 1775) e Blatta orientalis (Linnaeus, 1758) são praticamente onipresentes nas habitaçôes humanas em diversas regiōes do mundo (Cochran, 1982; Grandcolas, 1998a,b). Devido às poucas espécies que convivem com o homem e face aos hábitos que algumas espécies possuem de viver em ambientes como esgotos, bueiros, lixeiras e fossas sanitárias as baratas são os insetos que mais causam rejeição e são os insetos mais conhecidos da população humana. Há espécies que vivem e se reproduzem dentro das habitações enquanto outras vivem e se reproduzem fora das habitações (jardim, locais de acúmulo de lixo, fossas, latrinas, tubulaçōes de esgoto).

Este trabalho contribui para o reconhecimento das espécies sinantrópicas da cidade de Manaus, e informa sobre algumas espécies pouco conhecidas da população e de técnicos de empresas de controle de insetos.

\section{MATERIAL E MÉTODOS}

As baratas foram coletadas em 100 estabelecimentos, sendo 50 residenciais, 35 comerciais e 15 educacionais, na zona urbana de Manaus, localizados em diferentes bairros. Quatro embarcaçōes (barcos regionais) foram vistoriadas para ampliar a área de abrangência de coleta. A visita foi acompanhada, sempre que possível, por técnicos de uma empresa controladora de insetos. As baratas foram coletadas logo após a aplicação de inseticida por funcionários da empresa. Nos locais em que não houve aplicação de inseticida foram feitas coletas em caixas de esgoto, fossas, caixas de gordura, pias de cozinha, frestas em paredes de madeira, caixas de luz, gavetas de armários, etc. Os estágios imaturos encontrados, ootecas viáveis e ninfas, foram coletados manualmente e mantidos no laboratório para obtenção de adultos e identificação por comparação com material identificado por especialistas nas coleçôes do INPA e da UFAM.

As ootecas foram individualizadas em frascos de vidro de $200 \mathrm{ml}$, para facilitar a visualização e manipulação. Após a eclosão as ninfas foram mantidas nos mesmos frascos os quais foram etiquetados externamente e no interior de cada um foi colocado um tubo de papelão deitado no fundo do frasco para refúgio das baratas, ração de cachorro para alimentação e algodão umedecido para suprimento de água. Cada frasco foi telado com tecido organza, preso com elástico, para permitir a circulação de ar. A parte superior interna do frasco foi untada com vaselina para evitar a fuga por ocasião da manipulação das ninfas.

A limpeza do recipiente foi feita semanalmente para retirada de sujeira, restos de ração e evitar o mau cheiro. As ninfas de cada coleta foram mantidas nos frascos de vidro até que pudessem ser identificadas.

As informaçōes de cada inspeção foram anotadas em uma ficha padronizada. Após serem sacrificadas, as baratas foram alfinetadas, etiquetadas, identificadas e incorporadas ao acervo da coleção de invertebrados do INPA e da UFAM.

\section{RESULTADOS E DISCUSSÃO}

Nas inspeçōes em residências, restaurantes, hospitais, escolas, estabelecimentos comerciais e embarcações, 93\% foram positivas para baratas. A presença de adultos, ninfas, ootecas ou fezes foi contabilizada como inspeção positiva. Seis espécies foram coletadas: Periplaneta americana (Linnaeus, 1758), Periplaneta australasiae (Fabricius, 1775), Blatella germanica (Linnaeus, 1758), Supella longipalpa (Fabricius, 1798), Blaberus parabolicus Walker, 1868 e Pycnoscelus surinamensis (Linnaeus, 1758).

\section{Periplaneta americana (Figura 1)}

É conhecida popularmente como barata de esgoto, barata vermelha, barata americana, barata voadora. $\mathrm{O}$ adulto varia entre 40 e $50 \mathrm{~mm}$ de comprimento, excluindo as antenas. Foi a espécie urbana mais comum nas residências, hotéis, restaurantes. Foi registrada em $83 \%$ das inspeçōes realizadas. Tem distribuição circumtropical e segundo Mariconi (1999) ocorre em todas as cidades, vilas e povoados do Brasil. Vive em ambientes escuros, quentes e úmidos e aceita qualquer tipo de alimento. Foi encontrada predominantemente nas áreas externas das residências, em tubulaçóes, caixas de esgoto, latrinas e fossas. É, no entanto, encontrada freqüentemente no interior das residências, forrageia à noite e sua ocorrência diurna é indício de superpopulação.

\section{Periplaneta australasiae (Figura 2)}

Apesar do nome específico indicar a origem na Austrália e Ásia é uma espécie cosmopolita. É facilmente confundida com $P$. americana, embora o adulto seja um pouco menor, 30 a $35 \mathrm{~mm}$ de comprimento, excluindo a antena. Machos e fêmeas castanho-avermelhadas, com a faixa amarela estreita na base da margem costal da asa anterior distinta. Foi registrada esporadicamente apenas em barcos regionais, de transporte de mercadorias ou de passageiros, onde encontra ambiente propício à reprodução, abrigo e alimento. Tem distribuição predominantemente circuntropical. Vive em ambientes escuros, quentes e úmidos e aceita qualquer tipo de alimento. Forrageia à noite. 


\section{Blatella germanica (Figura 3)}

É conhecida popularmente como baratinha de cozinha, baratinha germanica ou alemanzinha. $\mathrm{O}$ adulto varia entre 10 e $15 \mathrm{~mm}$ de comprimento, excluindo as antenas. Os machos são castanho-amarelados e as fêmeas levemente mais escuras; o pronoto possui duas faixas longitudinais mais escuras em ambos os sexos. É cosmopolita e considerada a praga domiciliar mais comum e mais espalhada pelo mundo (Robinson, 1996; Roth, 1997). Foi a segunda espécie de barata urbana mais comum em Manaus registrada em 68\% das inspeçōes realizadas. É domiciliar e vive em ambientes escuros e de alta umidade, preferencialmente em armários de cozinhas e banheiros, mas podem ser encontradas em outros compartimentos, principalmente quando há alimento e água suficientes (Robinson, 1996). As fêmeas carregam a ooteca na extremidade do abdômen até o nascimento das ninfas (Roth, 1970).

\section{Supella longipalpa (Figura 4).}

É conhecida popularmente como baratinha de armário, baratinha listada, francesinha. $\mathrm{O}$ adulto varia entre $10 \mathrm{e}$ $14 \mathrm{~mm}$ de comprimento (excluindo as antenas). Pronoto uniformemente castanho-claro. Os machos são mais delgados, com as asas ultrapassando a extremidade abdominal. As fêmeas são mais robustas, com asas mais curtas deixando a extremidade do abdômen visível. Asas com bandeamento transversal amarelado, mais conspícuo nas fêmeas.

S. longipalpa (Fabricius, 1798) tem sido tratada como S. supellectilium (Serville, 1839) em alguns trabalhos (Albuquerque, 1964; Mariconi, 1999). S. supellectilium é, na realidade, sinônimo de $S$. longipalpa conforme Gutierrez (1995) e Grandcolas (1998a). É considerada uma praga com distribuição circumtropical. Em Manaus foi a terceira espécie de barata urbana mais comum, registrada em $55 \%$ das inspeçōes realizadas. É domiciliar e vive em ambientes escuros e, ao contrário de B. germanica, pode ser encontrada em todos os compartimentos de uma residência, não tem preferência pela cozinha e banheiros (Robinson, 1996).

\section{Pycnoscelus surinamensis (Figura 5).}

É conhecida popularmente como barata de jardim, barata da grama. $\mathrm{O}$ adulto varia entre 19 e $23 \mathrm{~mm}$ de comprimento, excluindo as antenas. É de cor predominante castanha. É uma espécie partenogenética que se reproduz sem necessidade de fecundação (Roth, 1998). Machos são raros e não foram encontrados na região amazônica. Foi coletada na área externa, onde vive e se reproduz nos jardins, áreas de cultivo ou de acúmulo de matéria orgânica em decomposição. É considerada uma praga com distribuição circuntropical. É citada por Grandcolas (1998a) como uma das espécies sinantrópicas. Para esta espécie, à semelhança de $P$. australasiae, não foi feito um levantamento criterioso como para as demais espécies.
Foi coletada em algumas residências com buscas direcionadas nas áreas externas. São invasoras ocasionais das habitações, principalmente na época chuvosa, quando fogem do excesso de água na parte externa. Não conseguem se estabelecer no ambiente interno das habitaçóes.

Tem baixa capacidade de vôo e é transportada pelo homem, tornando-se uma espécie restrita às proximidades das habitações humanas, ativas ou não, presentes em vários tipos de plantas onde se enterram no solo sombreado (Grandcolas et al., 1996) ou detritos acumulados na bainha das folhas, como do coqueiro (obs. pessoal do primeiro autor). Seu estabelecimento em diferentes áreas é facilitado pelo deslocamento de mudas de plantas pelo homem, às quais podem causar sérios danos (Roth 1979; Robinson 1996), mas não têm propensão de invadir ambientes naturais, inalterados (Grandcolas et al., 1996; Pellens \& Grandcolas, 2002).

\section{Blaberus parabolicus (Figura 6).}

É conhecida popularmente como barata grande, barata manchada, baratona. O adulto varia entre 55 e $83 \mathrm{~mm}$ de comprimento, excluindo as antenas. Machos e fêmeas possuem coloração castanho-amarelada com mancha preta quadrada no pronoto. Esta espécie pertence ao grupo "falsas ovovivíparas", por armazenarem internamente a ooteca num "saco" onde os ovos permanecem até a eclosão das ninfas.

Foi coletada na área externa, onde vive e se reproduz em locais de acúmulo de matéria orgânica em decomposição. É uma espécie silvestre, amazônica, que está se adaptando às proximidades das habitaçōes humanas. Foi coletada em algumas residências com buscas direcionadas nas áreas externas e, eventualmente, dentro de habitaçōes. Assim como a espécie anterior é invasora ocasional das habitações, principalmente na época chuvosa, quando fogem do excesso de água na parte externa ou quando seu ambiente é perturbado. Não conseguem se estabelecer no ambiente interno das habitações. B. parabolicus é bastante parecida com B. giganteus (Linnaeus, 1758 ) e pode ser diferenciada pelas asas anteriores (tégmina) sem a mancha escura presente em B. giganteus.

\section{CONSIDERAÇÕES FINAIS}

A identificação das espécies de baratas sinantrópicas é importante principalmente para os agentes controladores de insetos. Estes devem saber diferenciar as espécies de maior importância, aquelas que requerem tratamento químico quando em alta densidade populacional, daquelas de menor importância, que não requerem aplicação de inseticidas, pois são invasoras ocasionais de residências. Há, ainda, espécies muito parecidas morfologicamente que habitam ambientes diferentes e o conhecimento de tais espécies permite a otimização no combate as mesmas. 


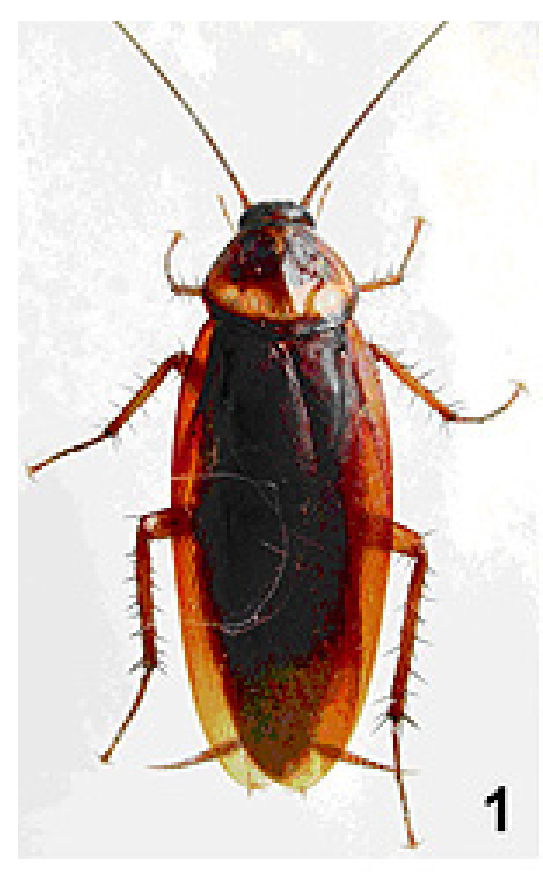

Figura 1 - Periplaneta americana

Figura 2 - Periplaneta australasiae (com manchas amarelas distintas)

Figura 3 - Blatella germanica (com duas faixas longitudinais pretas no pronoto), macho à esquerda

Figura 4 - Supella longipalpa macho (com manchas amarelas transversais nas asas)

Figura 5 - Pycnoscelus surinamensis

Figura 6 - Blaberus parabolicus com mancha preta, subquadrada no pronoto).
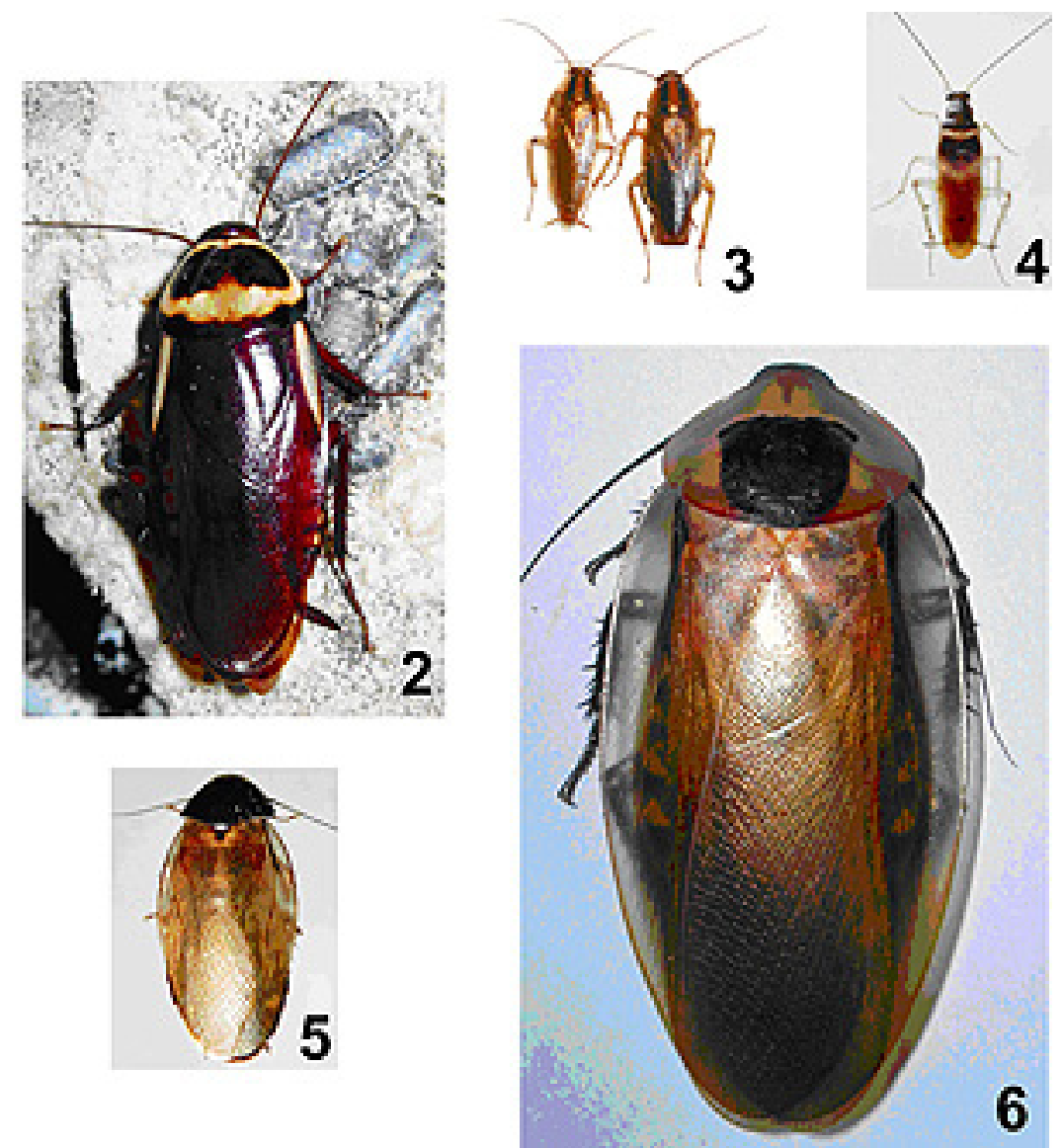

É importante reforçar que as baratas sinantrópicas proliferam-se abundantemente porque o homem fornece as condiçôes ideais para seu desenvolvimento e as transportam tão eficientemente que não há dificuldades de se desenvolverem e nem de se estabelecerem em diferentes locais. Para minimizar tais problemas o melhor método de combate para as espécies sinantrópicas é a limpeza dentro e fora dos domicílios ou estabelecimentos comerciais, evitando restos de alimento e acúmulo de lixo. Evitar, também, ambientes úmidos, escuros e sem ventilação e com muitas frestas, onde as baratas podem se esconder. As baratas domésticas são muito sensíveis ao ressecamento e têm atividade noturna, fugindo da luz. Além disto, as baratas se alimentam de fungos, que se desenvolvem prioritariamente neste tipo de ambiente. A aplicação de inseticida só é recomendável quando houver alto nível de infestação.

\section{AGRADECIMENTOS}

À Dra Roseli Pellens pelos comentários e sugestôes.

\section{BIBLIOGRAFIA CITADA}

Albuquerque, I.R.S. 1964. Ckeck-list dos Blattaria brasileiros. Boletim do Museu Paraense Emílio Goeldi, Zoologia, 41:1-37.

Cochran, D.G. 1982. Cockroaches, biology and control. Vector biology control \# 82856. Geneva: World Health Organization.54 pp.

Grandcolas, P. 1998a. Domestic and non-domestic cockroaches: facts versus received ideas. Revue Française Allergologie, 38(10):833838.

Grandcolas, P. 1998b. Les Blattes. Copenhagen, World Health Organization. 24 pp.

Grandcolas, P.; Pellens, R. (no prelo). Blattaria. In: Rafael, J.A.; Melo, G.A.R.; Carvalho, C.J.B.; Casari, S.A. \& R. Constantino (eds). Insetos do Brasil: Diversidade e Taxonomia. 
Grandcolas, P.; Dejean, A.; Deleporte, P. 1996. The invading parthenogenetic cockroach: a natural history comment on Parker and Niklasson's study. Journal of Evolutionary Biology, 9:1023-1026.

Gutiérrez, E. 1995. Annotated checklist of Cuban cockroaches. Transactions of the American Entomologist Society, 121(3): 6584.

Mariconi, F.A.M. (coord.). Insetos e outros invasores de residências. Biblioteca de Ciências Agrárias Luiz de Queiróz, volume 6, FEALQ, Piracicaba. 460pp.

Pellens, R.; Grandcolas, P. 2002. Are successful colonizers necessarily invasive species? The case of the so-called invading parthenogenetic cockroach, Pycnoscelus surinamensis, in the Brazilian atlantic forest. Revue d'Ecologie (Terre Vie) 57: 253261.

Pellens, R.; Grandcolas, P. 2008. Catalogue of Blattaria (Insecta) from Brazil. Zootaxa, 1709: 1-109.

Princis, K. 1962-71. Blattariae, p 1-1224. In: M. Beier (ed.) Orthopterorum Catalogus. Junk's-Gravenhage.
Robinson, W.H. 1996. Urban Entomology. Insect and mite pests in the buman environment. Chapman \& Hall, London. 430pp.

Roth, L.M. 1970. Evolution and taxonomic significance of reproduction in Blattaria. Annual Review of Entomology, 15: 75-96.

Roth, L.M. 1979. Cockroaches and plants. Horticulture, August. p. 12-13.

Roth, L.M. 1997. A new combination, and new records of species of Blatella Caudell (Blattaria: Blattellidae: Blattellinae). Oriental Insects, 31: 229-239.

Roth, L.M. 1998. The cockroach genus Pycnoscelus Scudder, with a description of Pycnoscelus femapterus, sp. n. (Blattaria: Blaberidae: Pycnoscelinae). Oriental Insects, 32: 93-130.

Recebido em 21/11/2006

Aceito em 23/06/2007 
